\title{
More Primary Care Appointments Scheduled With Advanced Practitioners by Medicaid Beneficiaries Post ACA Implementation
}

\author{
Jessica Tucker, DO, Grant Family Medicine; Michael E. Jobansen, MD, MS, Associate Editor \\ Ann Fam Med 2019;17(4):iii. https://doi.org/10.1370/afm.2437.
}

The Annals of Family Medicine encourages readers to develop a learning community to improve health care and

health through enhanced primary care. Participate by conducting a RADICAL journal club. RADICAL stands for Read, Ask, Discuss, Inquire, Collaborate, Act, and Learn. We encourage diverse participants to think critically about important issues affecting primary care and act on those discussions. ${ }^{1}$

\section{HOW IT WORKS}

In each issue, the Annals selects an article and provides discussion tips and questions. Take a RADICAL approach to these materials and post a summary of your conversation in our online discussion. (Open the article and click on "TRACK Discussion/ Submit a comment.") Discussion questions and information are online at: http://www.AnnFamMed.org/site/AJC/.

\section{CURRENT SELECTION}

\section{Article for Discussion}

Leszinsky L, Candon M. Primary care appointments for medicaid beneficiaries with advanced practitioners. Ann Fam Med. 2019;17(4):363-366.

\section{Discussion Tips}

This unique "secret shopper" study design utilized trained callers to simulate Medicaid patients in need of a primary care practice in 10 states in 2012, 2014, and 2016. The objective of this study was to determine the proportion of visits with advanced practice providers (APP) around the implementation of the Patient Protection and Affordable Care Act. As you discuss this, consider the ramifications of the findings as well as how different health care policies might impact the primary care workforce.

\section{Discussion Questions}

- What question is asked by this study and why does it matter?
- How does this study advance beyond previous research and clinical practice on this topic?

- How strong is the study design for answering the question?

- To what degree can the findings be accounted for by:

1. How patients/calls were selected, excluded, or lost to follow-up?

2. How the main variables were measured?

3. Confounding (false attribution of causality because 2 variables discovered to be associated actually are associated with a 3 rd factor)?

4. Chance?

5. How the findings were interpreted?

- What are the main study findings?

- What is your judgment about the transportability of the findings? Who, specifically, are these findings representative of?

- How strong are findings for individual states? What might lead to differences in absolute values between different states?

- What contextual factors are important for interpreting the findings?

- How might this study change your practice? Policy? Education? Research?

- Who are the constituencies for the findings, and how they might be engaged in interpreting or using the findings?

- What are the next steps in interpreting or applying the findings?

- What researchable questions remain?

\section{References}

1. Stange KC, Miller WL, McLellan LA, et al. Annals Journal Club: It's time to get RADICAL. Ann Fam Med. 2006;4(3):196-197. http:// annfammed.org/cgi/content/full/4/3/196. 